\title{
Featured papers on operational research and ethics
}

\author{
Fred Wenstøp ${ }^{1} \cdot$ Cristóbal Miralles $^{2} \cdot$ \\ Gerhard-Wilhelm Weber ${ }^{3}$
}

Published online: 5 May 2016

(C) Springer-Verlag Berlin Heidelberg and EURO - The Association of European Operational Research Societies 2016

From its inception, the Operational Research (OR) community has taken a keen interest in Ethics. An early voice is Kenneth Boulding's (1966) seminal paper "The Ethics of Rational Decision" where he lauds OR for its ability to take all stakeholders into account and find efficient solutions. This was followed by the “ORSA Guidelines for Professional Practice" (1971) which provided a list of OR analysts' virtues such as being open, explicit, objective, flexible and independent, to name a few. These first reflections led to a growing awareness in the last decades that there are always options in defining problems, and that the choice among these options has ethical implications which create a need for the development of problem-structuring methods. In this sense, ethical thinking in OR has been very much revived by several contributions of OR researchers [(see Gass (2009)] for an overview) and especially by the creation of the EURO Working Group (EWG) on "Ethics and OR" which has played a key role in motivating special issues on OR and Ethics in journals such as European Journal of Operational Research (2004); Omega (2009), and International Transactions in Operational Research (2010).

This new set of featured papers is motivated by the fact that Ethics is even more relevant for OR researchers today. OR methods and tools are steadily becoming more sophisticated, and the consequences of their applications more far-reachingand sometimes controversial. At the same time, the increasing use of social media

Gerhard-Wilhelm Weber

gweber@metu.edu.tr

$1 \quad$ Strategy and Logistics, BI Norwegian Business School, Nydalsveien 37, 0483 Oslo, Norway

2 Depto. Organización de Empresas, Universidad Politecnica de Valencia, Cami de Vera s/n, 46022 Valencia, Spain

3 Institute of Applied Mathematics, Middle East Technical University, 06531 Ankara, Turkey 
makes it possible to voice public concern about issues like environment impacts, sustainability, stakeholder values, fairness, health, civil rights, and due process. Thus, significant questions about virtues, principles and consequences are being raised. These questions cannot be resolved easily, because they belong to different ethical domains and touch us emotionally in different ways. One needs only to think of the furious public sentiment regarding the recent leakage of the Panama papers, where public officials and business leaders of thousands of companies are accused not so much of outright tax evasion but of lack of virtue, because they have hidden assets in tax havens and thus made tax evasion possible. In contrast to this, we also witness an intense struggle by companies to demonstrate that they are ethical. The number of non-financial reports issued worldwide has grown exponentially from almost nil in 1990 to about 5000 by 2010, and the number of hits on the term "Corporate social responsibility" in the media has grown from nothing to 18,000 in the same period (Ditlev-Simonsen and Wenstøp 2013).

This poses important challenges of which all OR researchers should be aware. At present, ethical dilemmas associated with the impacts that OR has on decision processes, for instance by influencing the conduct of decision makers or by affecting stakeholders or the environment, ought to be recognized as increasingly important by OR professionals. This is also why the Board of the EURO Working group on OR and Ethics took the initiative to invite featured papers for this special section on OR and Ethics.

This collection of the four featured papers has as a common theme: How to improve the Ethics of OR processes? Or more specifically: How can the ethical dimensions of virtues, principles and good consequences be promoted in a consistent and conscientious way?

The first paper, authored by Ulrike Reisach, is entitled "The Creation of Meaning and Critical Ethical Reflection in Operational Research". It is a philosophical paper that advocates that the operational researcher builds virtue through "creation of meaning". According to Reisach: "Everyhuman being has a legitimate right to set their own goals. Through doing so, each individual person can answer the question of meaning for their existence. The call for a "creation" of meaning, instead of "recognizing" a given one, frees the individual from any predetermination. It emphasizes the possibility of creating meaning through acting in the here and now of the real world instead of waiting for it to be revealed in the hereafter. Only the persons themselves can utilize their freedom and realize what they determine as being their unique duty and purpose. She develops and describes five major recommendations for ethical handling of business or community issues: (1) creation of meaning and value, (2) careful examination of the situation and its potential consequences, (3) stakeholder discourse, (4) innovation in methodology and approaches, and (5) analysis, reflection and learning.

The second paper, authored by Pierre Kunsch, is entitled "How System Dynamics education may enhance virtue-based Ethics". It advocates systemdynamics as a useful pedagogical tool for building virtues in students. He argues that the comprehensiveness of system-dynamics thinking may induce a cognitive transformation toward a holistic view on complex decision problems. This promotes central virtues such as respect, attentiveness, and wisdom. 
The third paper, authored by Søren Wenstøp and Fred Wenstøp, is entitled "Operational Research Virtues in the Face of Climate Change". Drawing on insights from the emerging field of affective neuroscience (Panksepp and Biven 2012), they probe the underlying reasons for the virulent debate around climate change, and argue that the virtue of righteousness is a central culprit. This complicates the notion of virtue, since it appears that virtues can also be vices, depending on the situation. In turn, the authors recommend virtues that are more conducive to consequential action with regard to mitigation and adaption in the face of climate change. These are humbleness instead of hubris with regard to geoengineering; accommodation with regard to restoration of nature; care and patience with regard to ecology; respect for people, respect for science, accuracy and concern with respect to work with mitigation and adaption; and finally, courage and factualism in the public debate.

The fourth paper, authored by Marc Le Menestrel and Luk Van Wassenhove, is entitled "Subjectively Biased Objective Functions". This paper is an important attempt to develop a rigorous framework for including subjective values, and in particular ethical values, into the objective function. The authors propose a methodological answer that relaxes the maximization principle by introducing a class of biased models that combine an objective function with a "subjective" factor that biases the maximization of such a function. They present an axiomatic foundation that allows for the rigorous measurement of biasing factors, and invite other researchers to contribute to further development and implementation of the ideas.

Acknowledgments The Guest Editors are very grateful to the founding Editor-in-Chief of EURO Journal on Decision Processes, Professor Ahti Salo (Aalto University School of Science, Finland), for giving a valuable platform to the challenging and emerging subjects of Ethics and OR and for his guidance at all stages of this featured cluster's preparation. They also wish EJDP readers a pleasant and enjoyable, instructive, and inspiring study of the contributions of these featured papers.

\section{References}

Boulding KE (1966) The ethics of rational decision. Manage Sci 12(6):B161-B169

Ditlev-Simonsen CD, Wenstøp F (2013) How stakeholders view stakeholders as CSR motivators. Social responsibility journal 9 NO 1 2013, pp 137-147, Q Emerald Group Publishing Limited, ISSN 1747-1117(1):137-147. doi:10.1108/17471111311307868

Gass SI (2009) Ethical guidelines and codes in operations research. Omega 37(6):1044-1050

ORSA (1971) Guidelines for professional practice. Oper Res 19(5):1127-1131

Panksepp J, Biven L (2012) The archaeology of mind. The Norton series on interpersonal neurology. W.W. Norton \& Company, London 